\title{
DRAFT
}

Forthcoming in John A. Rothchild (ed.), RESEARCH HANDBOOK ON ELECTRONIC COMMERCE LAW, Edward Elgar, 2016

\section{Copyright's Digital Deputies: DMCA-Plus Enforcement by Internet Intermediaries}

\author{
Annemarie Bridy*
}

\begin{abstract}
:
In the years since passage of the Digital Millennium Copyright Act ("DMCA"), the copyright industries have demanded that online intermediariesboth those covered by the DMCA and those falling outside the statute's ambit-do more than the law requires to protect their intellectual property rights. In particular, they have sought new ways to reach and shutter "pirate sites" beyond the reach of United States law. Their demands have been answered through an expanding regime of nominally voluntary "DMCA-plus" enforcement.

This chapter surveys the current landscape of DMCA-plus enforcement by dividing such enforcement into two categories: Type 1 and Type 2. Type 1 DMCAplus enforcement is cooperation by DMCA-covered intermediaries over and above what is required for safe harbor. Type 2 DMCA-plus enforcement is cooperation by intermediaries whose activities fall outside the scope of the DMCA's safe harbors and who are not liable for their customers' copyright infringements under secondary liability rules.

As the gap widens between what the law requires and what intermediaries are agreeing to do on a voluntary basis, there is reason to be concerned about the expressive and due process rights of users and website operators, who have no seat at the table when intermediaries and copyright owners negotiate "best practices" for mitigating online infringement, including which sanctions to impose, which content to remove, and which websites to block without judicial intervention.
\end{abstract}

\footnotetext{
* Professor, University of Idaho College of Law; Affiliate Scholar, Stanford Law School Center for Internet and Society (CIS).
} 


\section{DRAFT}

Forthcoming in John A. Rothchild (ed.), RESEARCH HANDBOOK ON ELECTRONIC COMMERCE LAW, Edward Elgar, 2016

\section{Introduction}

For the first dozen years after passage of the Digital Millennium Copyright Act ("DMCA"), the safe harbors in Section 512 set the parameters for cooperative online enforcement between Internet intermediaries and the copyright industries. ${ }^{1}$ The DMCA safe harbors account for both the types of online activities that typically give rise to secondary copyright liability and the types of service providers that typically engage in those activities. ${ }^{2}$ For example, the safe harbors cover routing and caching of third-party content by broadband Internet service providers ("ISPs"); ${ }^{3}$ storage of third-party content by hosting services and user-generated content ("UGC") platforms; ${ }^{4}$ and linking to third-party content by search engines. ${ }^{5}$ As long as covered service providers adhere to the applicable conditions for safe harbor in the DMCA by providing specified enforcement assistance, they are insulated from claims for money damages arising from their users' copyright infringements. ${ }^{6}$ The DMCA's quid pro quo is thus non-liability in exchange for limited aid from intermediaries whose relationship to acts of direct copyright infringement could otherwise leave them legally exposed. ${ }^{7}$

\footnotetext{
${ }^{1}$ See 17 U.S.C. $\$ 512$.

${ }^{2}$ A "service provider" is defined broadly in the DMCA as "a provider of online services or network access, or the operator of facilities therefor." 17 U.S.C. $\S 512(\mathrm{k})(1)(\mathrm{B})$.

${ }^{3}$ See 17 U.S.C. $\$ 512$ (a) (establishing a safe harbor for "transmitting, routing, or providing connections for, material through a system or network controlled or operated by or for the service provider").

${ }^{4}$ See 17 U.S.C. $\$ 512$ (c) (establishing a safe harbor for "storage at the direction of a user of material that resides on a system or network controlled or operated by or for the service provider"). The scope of Section 512(c) has been held to cover not only the storage of users' materials but also activities the service provider undertakes to provide users with access to their stored materials. See UMG Recordings, Inc. v. Shelter Capital Partners LLC, 718 F.3d 1006, 1018 (9th Cir. 2013) (holding that the safe harbor covers "access-facilitating processes" as well as storage).

${ }^{5}$ See 17 U.S.C. $§ 512(d)$ (establishing a safe harbor for "referring or linking users to an online location containing infringing material or infringing activity, by using information location tools, including a directory, index, reference, pointer, or hypertext link").

${ }^{6}$ Each of the four safe harbors provides that "[a] service provider shall not be liable for monetary relief" if the conditions for safe harbor are met. 17 U.S.C. $\$ 512(a),(b),(c), \&$ (d).

7 The legislative history of the statute documents this bargain. See S. REP. No. 105-190, at 20 (1998) ("Title II preserves strong incentives for service providers and copyright owners to cooperate to detect and deal with copyright infringements that take place in the digital networked environment. At the same time, it provides greater certainty to service providers concerning their legal exposure for infringements that may occur in the course of their activities.").
} 


\section{DRAFT}

Forthcoming in John A. Rothchild (ed.), RESEARCH HANDBOOK ON ELECTRONIC COMMERCE LAW, Edward Elgar, 2016

The copyright industries have never been satisfied with the bargain that was struck in the DMCA, however. In the words of the Motion Picture Association of America ("MPAA"), they are always looking for ways to "improve upon default legal standards (such as the DMCA)" and to exact promises of increased cooperation from "recalcitrant players." 8 As the Internet has grown exponentially in terms of both users and services, corporate rights owners and their trade groups have lobbied continuously for more aggressive enforcement from a wider range of intermediaries. In Congress, the courts, and the media, they have demanded that online intermediaries of all kinds do more to protect their intellectual property rights. ${ }^{9}$ In particular, they have sought new ways to reach and shutter "pirate sites" that are beyond the reach of U.S. law. ${ }^{10}$ In recent years, their demands have been answered through an expanding regime of "DMCA-plus" enforcement.

The arrangements that define DMCA-plus enforcement are nominally voluntary (i.e., contractual or quasi-contractual), but they come about largely as a result of political pressure and express or implied threats of governmental regulation. ${ }^{11}$ The Office of the U.S. Intellectual Property Enforcement Coordinator ("IPEC") has consistently promoted such arrangements in the form of privately negotiated "best practices" statements or agreements. ${ }^{12}$ In 2013, the House Judiciary Committee Subcommittee on Courts, Intellectual Property, and the Internet held a hearing to applaud existing private-sector voluntary agreements and

\footnotetext{
${ }^{8}$ Comments of the Motion Picture Ass'n of Am., Inc. ("MPAA") 2-3 (Aug. 21, 2013), submitted in U.S. PATENT AND Trademark OfFice, Voluntary Best Practices Study, Docket No. PTO-C-2013-0036, available at http://www.uspto.gov/ip/officechiefecon/PTO-C-2013-0036.pdf.

${ }^{9}$ See, e.g., id. at 2 (arguing that "all players in the Internet ecosystem," including "the various intermediaries that facilitate online commerce and speech...must play a meaningful role in addressing the problem of rampant piracy on the Web"); Comments of the Recording Indus. Ass'n of Am., Inc. ("RIAA") 1 (Aug. 19, 2013), submitted in U.S. PATENT AND TRADEMARK OFFICE, supra note 8 (asserting that "all responsible stakeholders in the Internet ecosystem... have a role to play in... deterring illegal activity").

${ }^{10}$ Their most controversial effort in this area was the famously failed lobbying campaign for the Stop Online Piracy Act (SOPA) and the PROTECT IP Act (PIPA). See generally Annemarie Bridy, Copyright Policymaking as Procedural Democratic Process: A Discourse-Theoretic Perspective on ACTA, SOPA, and PIPA, 30 Cardozo Arts \& Ent. L.J. 153 (2012).

${ }^{11}$ See Annemarie Bridy, Internet Payment Blockades, 67 FLA. L. REV. __ (forthcoming Sept. 2015) (discussing the government's role in procuring voluntary agreements and the "paradox of non-regulatory regulation" in the anti-piracy and anti-counterfeiting space).

12 See e.$g$. ., OFFICE OF THE U.S. INTELLECTUAL PROP. ENFORCEMENT COORDINATOR, 2013 JoINT STRATEGIC PLAN ON INTELLECTUAL PROPERTY ENFORCEMENT 35 (2013) (“As an Administration, we have adopted the approach of encouraging the private sector to develop and implement cooperative voluntary initiatives to reduce infringement that are practical and effective.") [hereinafter IPEC 2013 JOINT STRATEGIC PLAN].
} 


\section{DRAFT}

Forthcoming in John A. Rothchild (ed.), RESEARCH HANDBOOK ON ELECTRONIC COMMERCE LAW, Edward Elgar, 2016

to encourage their expansion. ${ }^{13}$ In the same year, the Patent and Trademark Office sought public comment on how a "Voluntary Best Practices Study" could be designed to quantify and evaluate the effectiveness of DMCA-plus agreements. ${ }^{14}$ Rights owners submitting comments for the study made it clear that they are looking to the government to police compliance: "[I]t is important that these voluntary initiatives be benchmarked and measured to determine whether the private sector can adequately 'self-regulate' to deter infringing and other abusive behavior." 15 In addition to pressure from the government, there are business reasons for some intermediaries to go beyond what the DMCA requires. As the online marketplace for digital entertainment evolves, intermediaries and copyright owners are increasingly financially co-dependent, whether through mass content-licensing deals or corporate mergers that vertically integrate content-distributing and copyright-owning enterprises. YouTube's Content ID system, discussed below, is a prime example of DMCA-plus enforcement as a symbiotic business relationship. ${ }^{16}$

The dilemma for intermediaries that volunteer to undertake DMCA-plus enforcement is that each new commitment they make raises the bar for what the copyright industries and policy makers regard as minimum standards. ${ }^{17}$ The more intermediaries give, it seems, the more is expected of them. In the DMCA-plus enforcement world, the gap between what the law requires and what intermediaries are promising to do is growing. As that gap widens, there is reason to be concerned about the expressive and due process rights of users and website operators, who have no seat at the table when intermediaries and copyright owners negotiate "best practices" for mitigating online infringement, including which sanctions to impose,

\footnotetext{
${ }^{13}$ See Role of Voluntary Agreements in the U.S. Intellectual Property System: Hearing Before the Subcomm. on Courts, Intellectual Prop., and the Internet of the H. Comm. on the Judiciary, 113th Cong. (2013).

${ }^{14}$ Request of the United States Patent and Trademark Office for Public Comments: Voluntary Best Practices Study, 78 Fed. Reg. 37,210 (2013).

${ }^{15}$ Comments of the RIAA, supra note 9, at 2.

${ }^{16}$ See Ramon Lobato \& Julian Thomas, The Business of Anti-Piracy: New Zones of Enterprise in the Copyright Wars, 6 INT'L J. COMMC'N 606, 612 (2012) (observing that Content ID "reflect[s] a significant reorientation in corporate IP policy, both by Google and various rights holders, toward a more pragmatic commercial engagement with copyright infringement").

${ }^{17}$ See, e.g., IFPI, DiGITAL MUSIC REPORT 42 (2014), available at http://www.ifpi.org/downloads/Digital-Music-Report-2014.pdf. ("Search engines have pledged to do more to tackle online piracy, but there is still a long way to go."); Comments of the MPAA, supra note 8, at 4 (expressing disappointment in the best practices adopted by advertising networks and characterizing them as "merely an incremental step forward").
} 


\section{DRAFT}

Forthcoming in John A. Rothchild (ed.), RESEARCH HANDBOOK ON ELECTRONIC COMMERCE LAW, Edward Elgar, 2016

which content to remove, and which websites to block without judicial intervention. ${ }^{18}$

This chapter surveys the current landscape of DMCA-plus enforcement by dividing such enforcement into two categories: Type 1 and Type 2. Type 1 DMCAplus enforcement is cooperation by DMCA-covered intermediaries over and above what is required for safe harbor. Type 1 enforcers include broadband ISPs, UGC platform operators, and search engines. As shown in the table below, Type 1 enforcers have adopted voluntary, DMCA-plus measures in the form of graduated response, link demotion, and proactive content blocking. Type 2 DMCA-plus enforcement is cooperation by intermediaries that are not secondarily liable for their customers' copyright infringements and are thus not motivated by the need for safe harbor. Type 2 enforcers include payment system operators and advertising networks. As shown in the table below, Type 2 enforcers have adopted notice and termination protocols. Domain name registrars are a third category of Type 2 intermediary now in the crosshairs of both the copyright industries and the government agencies that watch out for their interests-IPEC and the Office of the United States Trade Representative (“USTR"). ${ }^{19}$ Efforts to deputize domain name registrars are nascent and, therefore, beyond the scope of this project, but it bears mentioning that if the copyright industries get their way, registrars will become active DMCA-plus enforcers in the near future. ${ }^{20}$

\footnotetext{
${ }^{18}$ See Niva Elkin-Koren, After Twenty Years: Revisiting Copyright Liability of Online Intermediaries, in THE EVOLUTION AND EQUILIBRIUM OF COPYRIGHT IN THE DigitAL AGE 29, 45 (Susy Frankel \& Daniel Gervais eds., 2014) (asserting that voluntary agreements often lack adequate safeguards for securing users' rights).

${ }^{19}$ See MPAA \& RIAA Demand DNS Action Against 'Pirate' Domains, TorrentFreaK (May 14, 2015), https://torrentfreak.com/mpaa-riaa-demand-dns-action-against-pirate-domains-150514/ (reporting on a Congressional hearing at which a representative of the copyright industries testified that "domain name registrars ... like other intermediaries in the e-commerce environment ... must play their part to help address the plague of online copyright infringement"); IPEC 2013 JOINT STRATEGIC PLAN, supra note 12, at 36 ("[IPEC] will continue to facilitate and encourage dialogue among different private sector entities that make the Internet function, which may include domain name registries and registrars ...."); UNITED STATES TRADE REPRESENTATIVE, 2014 OUT-OF-CYCLE REVIEW OF NOTORIOUS MARKETS 10 ( 2015) (identifying domain name registrars as a "new issue focus" in the USTR's "Special 301" process for targeting notorious global markets for piracy and counterfeiting).

${ }^{20}$ See Comments of the MPAA, supra note 8, at 8 ("Although implementation is still in the early stages, MPAA remains optimistic that the new ICANN requirements will be an important tool for combating copyright infringement on a more global level."). But see Brian Fung, We Aren't the Copyright Cops, ICANN's President Says, WASH. Post, June 9, 2015, https://www.washingtonpost.com/blogs/the-switch/wp/2015/06/09/we-arent-the-copyright-police-
} 


\section{DRAFT}

Forthcoming in John A. Rothchild (ed.), RESEARCH HANDBOOK ON ELECTRONIC COMMERCE LAW, Edward Elgar, 2016

\begin{tabular}{|c|c|c|}
\hline $\begin{array}{l}\text { Enforcement } \\
\text { Type }\end{array}$ & Intermediary Type & DMCA-Plus Measure \\
\hline \multirow{3}{*}{1} & Broadband ISP & Graduated Response \\
\hline & Search Engine & Link Demotion \\
\hline & UGC Platform & Proactive Content Blocking \\
\hline \multirow[b]{2}{*}{2} & Payment Network & \multirow[b]{2}{*}{$\begin{array}{c}\text { Notice and } \\
\text { Termination/Blocking }\end{array}$} \\
\hline & Advertising Network & \\
\hline
\end{tabular}

\section{Type 1 DMCA-plus enforcement}

Type 1 DMCA-plus enforcement consists of voluntary, above-and-beyond measures that are undertaken by intermediaries whose compliance obligations are defined by the Section 512 safe harbors. To understand what it means for a service provider to exceed its safe-harbor obligations, it is first necessary to understand what those obligations are and how they vary depending upon the nature of the provider's operations and its relationship to allegedly infringing acts and actors.

To qualify for the statutory safe harbor, search engines and UGC platforms are required to comply with the notice-and-takedown protocol in Section 512(c) and with the obligation to terminate access for repeat infringers in Section 512(i). Under Section 512(c), a service provider is required, upon acquiring actual or "red flag" notice of a specific instance of infringement on its service, to promptly remove or disable access to the infringing content. ${ }^{21}$ Under Section 512(i), a service provider is required to adopt and reasonably implement a program for terminating account access for repeat infringers in appropriate circumstances. ${ }^{22}$ Broadband ISPs are not required to comply with the notice-and-takedown protocol in Section

\footnotetext{
says-icanns-president/ (reporting on the ICANN president's vow to avoid mission drift in the face of pressure from interest groups to have ICANN regulate content online).

${ }^{21}$ See 17 U.S.C. § 512(c) (setting forth the obligation of service providers seeking safe harbor to act promptly to take down allegedly infringing material upon receiving or acquiring notice that the material is infringing); § 512(c)(3)(A) (setting forth the required components of a DMCA notice). ${ }^{22}$ See 17 U.S.C. § 512(i) (requiring service providers to adopt and reasonably implement a policy for terminating the accounts of repeat infringers in appropriate circumstances and requiring service providers not to interfere with "standard technical measures" employed by copyright owners to prevent infringement of their works).
} 


\section{DRAFT}

Forthcoming in John A. Rothchild (ed.), RESEARCH HANDBOOK ON ELECTRONIC COMMERCE LAW,

Edward Elgar, 2016

512(c), because they do not control the content that transits their networks. ${ }^{23}$ They are, however, required to comply with the repeat infringer provision in Section 512(i). ${ }^{24}$

In no case is safe harbor for any provider under the DMCA conditioned on that provider's affirmatively monitoring its service for infringing activity. ${ }^{25}$ Notwithstanding the fact that this no-duty-to-monitor rule is explicit in Section 512(m), copyright owners have urged courts in high-profile litigation to hold that the DMCA's "red flag" notice provision implies a general obligation to monitor a site for infringement once a provider knows that some infringing content is present. $^{26}$ No court has ever accepted that argument, however, meaning that a service provider's prescribed enforcement role under the DMCA is reactive rather than proactive. ${ }^{27}$ To the great frustration of rights owners, courts interpreting the DMCA have been clear that notice and takedown does not equate with notice and staydown. Accordingly, the service provider is not required to block an allegedly infringing file from being re-uploaded to its service after the file has been taken down in response to a copyright owner's notice. ${ }^{28}$

Copyright owners have also urged courts to hold that the repeat infringer provision in Section 512(i) requires service providers to terminate users who have been the subject of multiple allegations of infringement in a single notice from a copyright owner. ${ }^{29}$ Another interpretation of the repeat infringer provision once

\footnotetext{
${ }^{23}$ See In re Charter Commc'ns, Inc., 393 F.3d 771, 776 (8th Cir. 2005) (noting that providers seeking safe harbor under $\S 512$ (a) do not have to comply with the DMCA's notice-and-takedown provisions).

${ }^{24}$ See Perfect 10, Inc. v. CCBill LLC, 488 F.3d 1102, 1109 (9th Cir. 2007) (stating that "[t]o be eligible for any of the four safe harbors at $\$ \S 512(a)-(d)$, a service provider must first meet the threshold conditions set out in $\S 512(\mathrm{i})$ ").

${ }^{25}$ See 17 U.S.C. $\$ 512(\mathrm{~m})(1)$ ("Nothing in this section shall be construed to condition the applicability of subsections (a) through (d) on . . . a service provider monitoring its service or affirmatively seeking facts indicating infringing activity.").

${ }^{26}$ See, e.g., UMG Recordings, Inc. v. Veoh Networks Inc., 665 F. Supp. 2d 1099, 1110 (C.D. Cal. 2009) ("UMG argues that Veoh should have sought out actual knowledge of other infringing videos by searching its system for all videos by the artists identified in the RIAA notices."), aff'd in relevant part sub nom. UMG Recordings, Inc. v. Shelter Capital Partners LLC, 718 F.3d 1006 (9th Cir. 2013).

${ }^{27}$ See id. ("Requiring Veoh to perform such searches would... conflict with the principle...that the DMCA notification procedures place the burden of policing copyright infringement...squarely on the owners of the copyright.") (internal citation and quotation marks omitted).

${ }^{28} C f$. id. at 1111 ("UMG has not established that the DMCA imposes an obligation on a service provider to implement filtering technology ....”).

${ }^{29}$ See id. at 1118 (declining to hold that Veoh was required to terminate access for a subscriber after a single notice alleging multiple instances of infringement).
} 


\section{DRAFT}

Forthcoming in John A. Rothchild (ed.), RESEARCH HANDBOOK ON ELECTRONIC COMMERCE LAW,

Edward Elgar, 2016

popular among rights owners is that a user should be "out" (i.e., have his or her account terminated or suspended) after a set number of "strikes" (i.e., consecutive notices of infringement) - usually three. ${ }^{30}$ That approach, known as graduated response, never took hold in the case law interpreting Section 512(i). ${ }^{31}$ Recognizing that Congress declined to specify any precise criteria for account termination when it adopted Section 512(i), no court has ever interpreted the DMCA's repeat infringer provision to require a provider to terminate a user's account after three (or any other specific number) of DMCA notices. ${ }^{32}$ The case law is mixed even on the basic question of whether a notice from a copyright owner, without more, can establish that a person is an infringer for statutory purposes. ${ }^{33}$

Whereas copyright owners have been unsuccessful in getting courts to interpret the DMCA to require proactive monitoring and graduated response, they have been successful in getting various service providers to agree to implement one or the other measure following private negotiations undertaken at the government's urging. In 2011, five of the largest broadband ISPs in the United States agreed in a Memorandum of Understanding ("MOU") with film and music industry trade

\footnotetext{
${ }^{30}$ Cf. Liza Porteus Viana, Three Strikes and You're Offline: Music Industry, ISPs May Cut Internet Access for File-Sharers, Fox NEws (Mar. 26, 2009), http://www.foxnews.com/story/2009/03/26/three-strikes-and-youre-offline-music-industry-ispsmay-cut-internet-access-for.html (reporting on the copyright industries' support for mandatory three-strikes repeat infringer policies).

${ }^{31}$ Adoption of a "three strikes" model of graduated response would be sufficient but is not necessary to bring a provider within the protection of the safe harbors with respect to Section 512(i). See Annemarie Bridy, Graduated Response and the Turn to Private Ordering in Online Copyright Enforcement, 89 OR. L. REV. 81, 100 (2010). See also Disney Enters., Inc. v. Hotfile Corp., No. 11-20427-CIV, 2013 WL 6336286, at*24 (S.D. Fla. Sept. 20, 2013) ("Although the Court is mindful that the DMCA does not specify the characteristics of a reasonably implemented policy, it is unaware of any situation in which a three-strikes policy has been found to be ineffective.").

${ }^{32}$ See Corbis Corp. v. Amazon.com, Inc., 351 F. Supp. 2d 1090, 1101 (W.D. Wash. 2004) (“Given the complexities inherent in identifying and defining online copyright infringement, § 512(i) does not require a service provider to decide, ex ante, the specific types of conduct that will merit restricting access to its services. As Congress made clear, the DMCA was drafted with the understanding that service providers need not make difficult judgments as to whether conduct is or is not infringing.") (internal citation and quotation marks omitted).

${ }^{33}$ Compare Perfect 10 v. CCBill, 340 F. Supp. 2d 1077, 1088 (C.D. Cal. 2004) (concluding that "an internet service provider who receives repeat notifications that substantially comply with the requirements of $\S 512(\mathrm{c})(3)(\mathrm{A})$ about one of its clients, but does not terminate its relationship with the client, has not reasonably implemented a repeat infringer policy"), rev'd in part on other grounds, 488 F.3d 1102 (9th Cir. 2007) with Corbis, 351 F. Supp. 2d at 1105 (concluding that notices from a copyright owner function to bring a potential infringement to the provider's attention, but do not, in themselves, provide evidence of blatant copyright infringement, because they could be erroneous).
} 


\section{DRAFT}

Forthcoming in John A. Rothchild (ed.), RESEARCH HANDBOOK ON EleCtronic COMMERCE LAW, Edward Elgar, 2016

groups to implement a "six strikes" graduated response protocol for mitigating unauthorized peer-to-peer file sharing. ${ }^{34}$ In 2007 and 2014, respectively, UCG platforms YouTube and Vimeo began proactively filtering user uploads to block files that match reference files in a database populated by rights owners. ${ }^{35}$ In addition, in 2012, Google voluntarily altered its search algorithm to demote "pirate sites" in search rankings. ${ }^{36}$ What follows is a detailed discussion of these Type I DMCA-plus implementations.

\section{A. Graduated response by broadband ISPs}

The "six strikes" MOU creates what the parties characterize as a "common framework of 'best practices' to effectively alert subscribers, protect copyrighted content and promote access to legal online content." 37 The participating ISPs are AT\&T, Verizon, Comcast, Cablevision, and Time Warner. ${ }^{38}$ The participating copyright owners are the MPAA, the Recording Industry Association of America ("RIAA"), the American Association of Independent Music ("A2IM"), and the Independent Film and Television Alliance ("IFTA"). ${ }^{39}$ At the core of the common framework is the Copyright Alert System ("CAS"), a privately designed and administered enforcement system to which members of the public opt in through contractual terms of service with their broadband providers. ${ }^{40}$ CAS operations are overseen by a specially created entity called the Center for Copyright Information

\footnotetext{
${ }^{34}$ See Annemarie Bridy, Graduated Response American Style: "Six Strikes" Measured Against Five Norms, 23 FordHAM INTELL. PROP. MEDIA \& ENT. L.J. 1 (2012) [hereinafter Bridy, Graduated Response American Style]; Mary LaFrance, Graduated Response by Industry Compact: Piercing the Black Box, 30 CARDOZO ARTS \& ENT. L.J. 165 (2012).

${ }^{35}$ See Steve Chen, The State of Our Video ID Tools, Google OfFICIAL Blog (June 14, 2007), http://googleblog.blogspot.com/2007/06/state-of-our-video-id-tools.html (announcing beta testing of Content ID); David Murphy, Vimeo Rolls Out “Copyright Match” for Flagging Content, PCMAG.COM (May 22, 2014), http://www.pcmag.com/article2/0,2817,2458440,00.asp.

${ }^{36}$ See Chloe Albanesius, Google to Demote Sites with "High Number" of Copyright Complaints, PCMAG.COM (Aug. 10, 2012), http://www.pcmag.com/article2/0,2817,2408341,00.asp.

${ }^{37}$ Mike Palmedo, Content Owners and ISPs Announce System of "Copyright Alerts" and “Mitigation Measures," INFOJUSTICE.ORG (July 7, 2011), http://infojustice.org/archives/4145.

38 See MEMORANDUM OF UNDERSTANDING 24 (Attachment A) (July 6, 2011), available at http://www.copyrightinformation.org/wp-content/uploads/2013/02/Memorandum-ofUnderstanding.pdf [hereinafter MOU] .

${ }^{39} I d$. at 25 (Attachment B).

${ }^{40} I d$. at 7 (requiring party ISPs to amend their terms of service or acceptable use policies to incorporate CAS).
} 


\section{DRAFT}

Forthcoming in John A. Rothchild (ed.), RESEARCH HANDBOOK ON ELECTRONIC COMMERCE LAW,

("CCI"). ${ }^{41}$ CAS applies only to users of residential broadband services and is intended to address infringement only over P2P networks. ${ }^{42}$

The CAS protocol consists of an escalating sequence of six warnings, or "copyright alerts," separated by seven-day grace periods. ${ }^{43}$ To begin the process, a copyright owner sends a notice of infringement to a subscriber's ISP, which then generates an alert and sends it to the subscriber whose Internet protocol ("IP") address was identified in the notice. ${ }^{44}$ To prevent ISPs from being overwhelmed by an unmanageable volume of notices, the MOU requires participating copyright owners to allocate among themselves an unspecified (but presumably fixed) number of notices per month. ${ }^{45}$ In addition to that limit, ISPs have discretion to temporarily stop processing notices if the demand on their systems and resources becomes unreasonable. ${ }^{46}$ Any temporary stoppage must be followed, however, by prompt notice to copyright owners and a collaborative effort to correct the "overprovisioning." 47

The first two copyright alerts are educational in nature and require no response or action from the subscriber. ${ }^{48}$ They explain that copyright infringement is illegal, that there are lawful ways of obtaining copyrighted content, and that users who persist in infringing copyrights will be subject to sanctions. ${ }^{49}$ The third and fourth alerts contain sterner language and require the subscriber to acknowledge receipt. ${ }^{50}$ The required acknowledgment can occur by means of either a clickthrough pop-up window or a click-through landing page to which the user's browser is diverted. ${ }^{51}$ At the acknowledgment stage, the subscriber must indicate that he or she agrees to immediately stop any infringing conduct in which he or she may have been engaged. ${ }^{52}$

${ }^{41} I d$. at 3-4.

${ }^{42}$ See id. at 2 (defining the scope of the program).

${ }^{43} I d$. at 7 . An ISP may send additional alerts during grace periods, but those alerts do not count toward the total number of six. Id. at 10.

${ }^{44} I d$. at 7.

${ }^{45} I d$. at 16.

${ }^{46} \mathrm{Id}$.

${ }^{47} I d$.

${ }^{48} I d$. at 8-9. An ISP may elect to send only one educational alert instead of two. See id. at 8 . The default number of alerts contemplated in the MOU, however, is six, with four coming after an initial "educational" step. Id. at 7-8.

${ }^{49} I d$. at 8 .

${ }^{50} I d$. at $9-10$.

${ }^{51} I d$. at 10.

${ }^{52} I d$. The subscriber also "agrees to instruct other users of the Subscriber's account to cease infringing conduct, if any exists." Id. 


\section{DRAFT}

Forthcoming in John A. Rothchild (ed.), RESEARCH HANDBOOK ON ELECTRONIC COMMERCE LAW,

Sanctions, or "mitigation measures," are not triggered until a fifth alert is sent. ${ }^{53}$ The MOU avoids being prescriptive when it comes to sanctions, specifying instead a range of mitigation measures from which ISPs can choose. ${ }^{54}$ Such measures include, but are not limited to, a temporary reduction in transmission speed, a temporary step-down in the subscriber's service tier, a temporary redirection to a landing page for completion of a program of copyright instruction, a temporary redirection to a landing page until the subscriber contacts a customer service representative, or a temporary suspension of access. ${ }^{55}$ No ISP operating under the MOU is required to suspend access for any subscriber. ${ }^{56}$ (This point should be emphasized, because it represents a departure from the typical graduated response model, which prescribes termination of a user's account after a set number of "strikes.") In lieu of imposing a mitigation measure with the fifth alert, the ISP may elect to waive the measure and send a standalone fifth warning alert. ${ }^{57}$ The sixth alert, however, must be accompanied by some mitigation measure. ${ }^{58}$ The mitigation measure can be the same one that was applied with the fifth alert, assuming the sanction was not waived at that stage, or a different one. ${ }^{59}$ After the sixth alert has been sent, the ISP has no further obligation to continue sending alerts to the subscriber, but it is required to keep count of any additional notices received from copyright owners concerning that subscriber. ${ }^{60}$ At every stage, the system will "reset" for the subscriber if twelve months pass without the receipt of an additional alert. $^{61}$

Before any mitigation measure is imposed, the recipient of a fifth or sixth alert has fourteen days to appeal the alert via a non-judicial process outlined in the MOU. ${ }^{62}$ The appeal process, which the MOU calls the "Independent Review Program," is a non-exclusive dispute resolution system administered by the American Arbitration Association ("AAA") under contract with CCI. ${ }^{63}$ The copyright owner representative and ISP groups split the overall costs of administration. ${ }^{64}$ At the individual case level, an appealing subscriber pays a thirty-

${ }^{53} \mathrm{Id}$. at $10-12$.

${ }^{54} \mathrm{Id}$. at 11-12.

${ }^{55} \mathrm{Id}$.

${ }^{56}$ Id. at 12.

${ }^{57} \mathrm{Id}$.

${ }^{58} I d$. at $12-13$.

${ }^{59} \mathrm{Id}$.

${ }^{60} \mathrm{Id}$. at 13.

${ }^{61}$ Id.

${ }^{62} \mathrm{Id}$. at 14 .

${ }^{63}$ Id. at 26 (Attachment C); Center for Copyright Information Announces Three Major Steps Towards Implementation, (Apr. 2, 2012), http://www.copyrightinformation.org/pressrelease/center-for-copyright-information-announces-three-major-steps-towards-implementation/.

${ }^{64}$ MOU, supra note 38, at 14. 


\section{DRAFT}

Forthcoming in John A. Rothchild (ed.), RESEARCH HANDBOOK ON ELECTRONIC COMMERCE LAW,

five dollar filing fee, which AAA may waive at its discretion. ${ }^{65}$ The filing fee is refundable if the subscriber prevails in his or her appeal. ${ }^{66}$ The appeal process is designed to be "automated to the maximum extent practicable." 67

A single reviewer chosen by AAA from a panel of neutrals decides each appeal. ${ }^{68}$ Reviewers must be lawyers, but they need not have the level of legal and case management experience that AAA arbitrators deciding other kinds of cases have. ${ }^{69}$ All reviewers deciding CAS appeals are trained by a AAA-commissioned, CCI-approved copyright expert to apply prevailing legal principles as determined by federal courts. ${ }^{70}$ By the terms of the MOU, this copyright expert must agree to receive input from the participating copyright owners as well as ISPs concerning what the prevailing legal principles are. ${ }^{71}$

A subscriber initiates an appeal by completing an online form wherein the subscriber asserts a defense or defenses to the allegations in the alert. ${ }^{72}$ The MOU limits a subscriber's grounds for review to exactly six: (1) account misidentification; (2) unauthorized use of account; (3) authorized use of content; (4) fair use; (5) misidentification of content; and (6) work published before $1923 .{ }^{73}$ The MOU mentions no other defenses, although a number of other defenses to copyright infringement claims are available to defendants in civil cases brought under the Copyright Act. ${ }^{74}$ With respect to each of the six possible grounds for review, the burden of proof is on the subscriber, effectively creating a presumption of infringement. ${ }^{75}$ Unless the subscriber overcomes that presumption, thereby winning her appeal, her ISP will impose a sanction.

When asserting one or more of the six cognizable grounds for review, the subscriber must provide sufficient factual information to allow the reviewer to evaluate the merits of the defense(s). ${ }^{76}$ Once an appeal has been initiated, the reviewer also receives a standard package of information concerning the subscriber's contacts with CAS leading up to the appeal. ${ }^{77}$ The reviewer may

${ }^{65} \mathrm{Id}$. at 30 .

${ }^{66} \mathrm{Id}$. at 28.

${ }^{67} \mathrm{Id}$. at 34 .

${ }^{68} \mathrm{Id}$. at 31.

${ }^{69} \mathrm{Id}$. at 33 .

${ }^{70} \mathrm{Id}$. at 35 .

${ }^{71} I d$. at 35 .

${ }^{72} I d$. at 29.

${ }^{73} I d$. at 26.

${ }^{74}$ See 17 U.S.C. $\$ \S 107-122$ (limitations on exclusive rights).

${ }^{75}$ See MOU, supra note 38, at 26-28 (explaining the standard of review for each of the six defenses).

${ }^{76} \mathrm{Id}$. at 29.

${ }^{77} \mathrm{Id}$. at $31-32$. 


\section{DRAFT}

Forthcoming in John A. Rothchild (ed.), RESEARCH HANDBOOK ON ELECTRONIC COMMERCE LAW, Edward Elgar, 2016

request supplemental information from the copyright owner or the ISP if she needs such information to decide the appeal. ${ }^{78}$ Beyond requests for supplemental information, the MOU provides that there be no communication concerning pending appeals among the reviewer, the ISP, the copyright owner, and the subscriber. ${ }^{79}$ The entire appeal process is designed to be completed within ten days of the reviewer's receipt of a complete file and within about thirty days of the initiation of the appeal. ${ }^{80}$ If the subscriber prevails, the copyright alert in question is invalidated. ${ }^{81}$

In light of the program's light sanctions and educational focus, CAS has not been as controversial an implementation of graduated response as some of the more draconian "three strikes" programs operating abroad, which can entail monetary fines and sustained Internet disconnection. ${ }^{82}$ In its first year of operation, CAS sent 1.3 million copyright alerts to broadband subscribers. It reported that it expected to double that number in $2014 .{ }^{83}$ More than seventy percent of alerts fell within the first two steps of the process: education and acknowledgement. Fewer than three percent were sent in the final step of the protocol, at which imposition of a mitigation measure is mandatory. ${ }^{84}$ Recipients of alerts filed 265 requests for review with AAA, 47 of which were successful. ${ }^{85} \mathrm{CCI}$ 's claims for the program during its first year of operation were modest. In its end-of-year report, it asserted that the program's educational message is reaching consumers, and it expressed the view that CAS will be even more effective when it scales up to reach a wider population of P2P users. ${ }^{86}$ Time will tell. Scholars evaluating France's statutory graduated response program, Hadopi, have been mixed in their empirical assessments of its efficacy for reducing infringement and steering users toward licensed services. ${ }^{87}$

\footnotetext{
${ }^{78}$ Id. at 32.

${ }^{79} \mathrm{Id}$. at 33.

${ }^{80}$ See id. at 31-35 (prescribing deadlines for successive phases of the review process).

${ }^{81} \mathrm{Id}$. at 28.

${ }^{82}$ See Rebecca Giblin, Evaluating Graduated Response, 37 COLUM. J.L. \& ARTS 147 (2014) (surveying statutory graduated response programs in France, New Zealand, South Korea, Taiwan, and the United Kingdom).

${ }^{83}$ CTR. For Copyright Info., The Copyright Alert System: PhASE OnE AND Beyond 1 (2014), available at http://www.copyrightinformation.org/wp-content/uploads/2014/05/PhaseOne-And_Beyond.pdf.

${ }^{84} I d$.

${ }^{85} \mathrm{Id}$.

${ }^{86} \mathrm{Id}$. at 3.

${ }^{87}$ Compare, e.g., Brett Danaher et al., The Effect of Graduated Response Anti-Piracy Laws on Music Sales: Evidence from an Event Study in France, 62 J. INDUS. ECON. 541, 542 (2014) (finding that increased consumer awareness of a graduated response law in France caused iTunes music sales in France to increase by 22-25\%) with Michael Arnold et al., Graduated Response
} 


\section{DRAFT}

Forthcoming in John A. Rothchild (ed.), RESEARCH HANDBOOK ON ELECTRONIC COMMERCE LAW, Edward Elgar, 2016

\section{B. Proactive filtering by UGC platforms}

Although the DMCA does not impose an affirmative monitoring obligation on intermediaries seeking safe harbor, the popular video-sharing sites YouTube and Vimeo offer content screening and filtering tools that can be configured by copyright owners to block users from uploading copyrighted content. Each platform implemented its program - Content ID for YouTube; Copyright Match for Vimeo-while copyright litigation was pending against it in federal court. Google launched Content ID shortly after acquiring YouTube and getting sued by Viacom and other copyright industry plaintiffs for billions of dollars in statutory damages. ${ }^{88}$ Vimeo adopted Copyright Match not long after it was handed a mixed summary judgment ruling in a lawsuit brought by Capitol Records and other record labels. ${ }^{89}$ In both cases, Google and Vimeo asserted the DMCA's Section 512(c) safe harbor as an affirmative defense to the plaintiffs' claims of copyright infringement.

Content ID and Copyright Match preempt the DMCA's reactive contentremoval mechanism by giving copyright owners the option to prevent disputed content from "going up" in the first place. The technology underlying both systems relies on digital fingerprinting to sample an uploaded file and compare it against a database of reference files provided by participating copyright owners. ${ }^{90}$ With Content ID, if the comparison between an uploaded file and a reference file results in a match, Google will apply one of four policies, based on what the copyright owner elected when it enrolled in the program: (1) it will mute matched audio in an uploaded video; (2) it will completely block a matched video; (3) it will monetize

\footnotetext{
Policy and the Behavior of Digital Pirates: Evidence from the French Three-Strike (Hadopi) Law (May 28, 2014), available at http://ssrn.com/abstract=2380522 (concluding that the French graduated response law has had no significant deterrent effect).

${ }^{88}$ See Viacom Int'l, Inc. v. YouTube, Inc., 676 F.3d 19 (2d Cir. 2012).

${ }^{89}$ See Capitol Records, LLC v. Vimeo, LLC, 972 F. Supp. 2d 500 (S.D.N.Y. 2013) (denying in part Vimeo's motion for summary judgment); Todd Spangler, Vimeo Starts Scanning Videos for Copyright Violations, VARIETY (May 21, 2014), https://variety.com/2014/digital/news/vimeostarts-scanning-videos-for-copyright-violations-1201188152/ (reporting on Vimeo's launch of Copyright Match).

${ }^{90}$ See Brad Stone \& Miguel Helft, New Weapon in Web War over Piracy, NY TIMES (Feb. 19, 2007), http://www.nytimes.com/2007/02/19/technology/19video.html (discussing fingerprinting technologies for identifying audio and video). For a technical discussion of how fingerprinting is used to identify copyrighted content, see Craig Seidel, Content Fingerprinting from an Industry Perspective, IEEE 2009, 1524-1527.
} 


\section{DRAFT}

Forthcoming in John A. Rothchild (ed.), RESEARCH HANDBOOK ON ELECTRONIC COMMERCE LAW, Edward Elgar, 2016

a matched video for the copyright owner by running advertisements against it; or (4) it will track a matched video's viewership statistics. ${ }^{91}$ According to Google, most copyright owners elect to monetize content, making Content ID both an antipiracy tool and a revenue generator for Google and copyright owners, which share the ad-generated revenue. ${ }^{92}$

Content ID's policies can be tailored, so that copyright owners can block uploaded content in some instances and monetize in others, depending on the extent to which an uploaded file and its corresponding reference file match. ${ }^{93}$ For example, a copyright owner can elect to monetize an uploaded video that contains less than a specified amount or proportion of matched content while blocking any uploaded video that contains more. ${ }^{94}$ The system is also capable of blocking audio and video independently of each other, so that the video portion of an uploaded file containing a matched copyrighted sound recording can stay up even if the sound recording copyright owner wants the audio portion blocked. ${ }^{95}$ In such cases, Google offers users the ability to swap a licensed sound recording file for the blocked one. ${ }^{96}$

Vimeo has not stated publicly what options it gives to participating copyright owners, but Audible Magic, the technology vendor with which Vimeo contracts for the service, describes a process in which the copyright owner's "business rules"-indicating whether matched content should be blocked or allowed - are automatically conveyed to its customer along with confirmation of a match. ${ }^{97}$ The company's literature goes on to explain that copyright owners and UGC platforms sometimes negotiate direct licensing agreements and specify business rules that include tracking or monetization. ${ }^{98}$ Based on Audible Magic's general description of the service it provides to Vimeo, Copyright Match closely resembles Content ID in terms of the options it makes available to copyright owners.

${ }^{91}$ How Content ID Works,YouTuBE, https://support.google.com/youtube/answer/2797370?hl=enGB.]

92 Google, How Google Fights PIRACY 10 (2014), available at https://drive.google.com/file/d/0BwxyRPFduTN2NmdYdGdJQnFTeTA/view.

${ }^{93}$ Kyle Harrison, Over 1,000 Content Owners Now Using Content ID, YouTuBE BIZ BLOG (Sept. 16, 2009), http://ytbizblog.blogspot.com/2009/09/over-1000-content-owners-now-using.html.

${ }^{94} I d$.

${ }^{95} I d$.

${ }^{96}$ What Is a Content ID Claim?, YouTuBE, https://support.google.com/youtube/answer/6013276?hl=en.

97 Audible Magic, Copyright Compliance Service: Compliance Automation for Media Sharing Platforms, AUDIBLE MAGIC, https:/www.audiblemagic.com/compliance-service/\#how-it-works/. ${ }^{98} I d$. 


\section{DRAFT}

Forthcoming in John A. Rothchild (ed.), RESEARCH HANDBOOK ON ELECTRONIC COMMERCE LAW,

Edward Elgar, 2016

Both programs allow users to dispute a copyright owner's claim on content. With Content ID, a user can dispute a claim if she believes the system misidentified her uploaded video or if she has the rights required to use the video. ${ }^{99}$ Google provides a fillable web form for submitting Content ID disputes. After a user has submitted a dispute, the copyright owner has thirty days to respond. If the copyright owner fails to respond within thirty days, the claim expires. A responding copyright owner can choose to either release the claim or uphold the claim. If the copyright owner upholds the claim, the user can appeal if she acts within a set period of time and has a verified account in good standing. If the user appeals, the copyright owner again has thirty days to respond and can either release the claim or file a DMCA takedown notice to have the content removed. With Copyright Match, a user can dispute a match on grounds that she is using the content with permission, she is using the content in keeping with fair use, or she is using content that the system misidentified. ${ }^{100}$ Like Content ID, Copyright Match allows a user to prevent a video containing claimed audio from being blocked by swapping the claimed audio track with a licensed track from Vimeo's catalog.

In 2014, Google reported that the Content ID program generates hundreds of millions of dollars in revenue per year for over 5,000 partners that have contributed more than 25 million active reference files to the database. ${ }^{101}$ The system, it seems, is working well for both Google and copyright owners. Some users have complained, however, that the system overblocks, that it presumes a user's guilt by automatically diverting revenue to a copyright owner as soon as a claim is filed, and that its dispute resolution process can take up to a month to play out. $^{102}$

\section{Search demotion}

\footnotetext{
${ }^{99}$ Dispute a Content ID Claim, YouTUBE, https://support.google.com/youtube/answer/2797454.

${ }^{100}$ Copyright Match,VIMEO, https:/vimeo.com/help/faq/legal-stuff/copyright-match/.

${ }^{101}$ GoOGLE, supra note 92, at 3, 10.

${ }^{102}$ See Erik Kain, YouTube Responds to Content ID Crackdown, Plot Thickens, Forbes.COM (Dec. 17, 2013), http://www.forbes.com/sites/erikkain/2013/12/17/youtube-responds-to-content-idcrackdown-plot-thickens/ (documenting cases of overblocking); Paul Tassi, The Injustice of the YouTube Content ID Crackdown Reveals Google's Dark Side, FORBES.COM (Dec. 19, 2013), http://www.forbes.com/sites/insertcoin/2013/12/19/the-injustice-of-the-youtube-content-idcrackdown-reveals-googles-dark-side/ (complaining about presumption of guilt, automatic revenue diversion, and lengthy dispute resolution).
} 


\section{DRAFT}

Forthcoming in John A. Rothchild (ed.), RESEARCH HANDBOOK ON ELECTRONIC COMMERCE LAW, Edward Elgar, 2016

A search engine operator is potentially liable for contributory copyright infringement, insofar as it "substantially assists websites to distribute their infringing copies to a worldwide market and assists a worldwide audience of users to access infringing materials." 103 Search engines fall within the scope of the DMCA's safe harbor for "information location tools" and are required to comply with the notice and takedown protocol in Section 512(c) as a condition for safe harbor eligibility. Operationally speaking, a search engine indexes the entire contents of the public World Wide Web in order to return relevant and comprehensive search results in response to user queries. When a search engine user queries a popular song or film title, the results returned - to the extent that they are complete-will inevitably include links to "pirate sites." How prominently those links are featured is a major source of disagreement between trade groups representing corporate copyright owners and those representing search providers.

According to the International Federation for the Phonographic Industry ("IFPI"), a music industry trade group, links to websites containing infringing content dominate search results for all three major search engines (Google, Yahoo!, and Bing), and almost three-quarters of consumers surveyed said they used search engines as a "discovery or navigational tool" to find unlicensed services. ${ }^{104}$ The Computer and Communications Industry Association ("CCIA"), a trade group to which Google and the other major search providers belong, countered those findings, citing a statistic that only fifteen percent of traffic to alleged "pirate sites" was referred by search engines. ${ }^{105}$ Moreover, the CCIA asserted, operators of licensed content services do little to optimize their sites in ways that would organically improve their search rankings. ${ }^{106}$ Such public sparring across industry trade groups is a clear sign that search has become a major battleground in the Internet's ongoing copyright wars. When it comes to policy makers, it appears that the copyright industries are landing their punches. In a Congressional hearing in 2014 on possible amendments to the DMCA safe harbors, members of the House Judiciary Committee Subcommittee on Courts, Intellectual Property, and the

\footnotetext{
103 Perfect 10, Inc. v. Amazon.com, Inc., 508 F.3d 1146, 1172 (9th Cir. 2007).

${ }^{104}$ IFPI, DigiTAL MUSIC REPORT 29 (2013), available at http://www.ifpi.org/content/library/DMR2013.pdf; IFPI, DIGITAL MUSIC REPORT (2014), supra note 17 , at 42.

105 MATT SCHRUERS, THE SEARCH FIXATION: INFRINGEMENT, SEARCH RESUlTS, AND ONLINE CONTENT 2 (2013), available at http://cdn.ccianet.org/wpcontent/uploads/2013/08/CCIA_TheSearchFixation.pdf.

106 Id. at 5.
} 


\section{DRAFT}

Forthcoming in John A. Rothchild (ed.), RESEARCH HANDBOOK ON ELECTRONIC COMMERCE LAW,

Internet peppered Google's representative with questions about what more Google can do with search to voluntarily fight online piracy. ${ }^{107}$

As the dominant player in the market for online search, Google has been a primary target of anti-piracy efforts for the film and music industries. ${ }^{108}$ Industry trade groups and some of their larger member firms contract with a growing number of third party vendors to both identify infringing links in web searches and send DMCA takedown notices to Google and other search providers. ${ }^{109}$ In recent years, Google has streamlined the takedown process for search by designing and implementing automated tools for bulk submission of Section 512 notices. ${ }^{110}$ These tools include the Trusted Copyright Removal Program, which allows large copyright owners with a proven track record for submitting accurate notices to become "trusted partners" for the purpose of submitting DMCA notices in bulk. ${ }^{111}$ The number of links Google removes from search results in response to copyright notices on an annual basis is staggering. For example, in 2013, Google removed over 222 million links to unique web addresses (URLs). ${ }^{112}$ It reports that the average turnaround time for the removal of a link subject to a copyright owner notice is now less than six hours. ${ }^{113}$ In copyright litigation over its content removal practices for search, Google has been held to qualify for the Section 512(d) safe harbor. ${ }^{114}$

The film and music industries argue, however, that bulk removal of links from search results is insufficient cooperation from search engine operators. ${ }^{115}$ The

\footnotetext{
107 See Section 512 of Title 17: Hearing Before the Subcomm. on Courts, Intellectual Prop., and the Internet of the H. Comm. on the Judiciary, 113th Cong. (2014), at $82 \mathrm{ff}$.

108 See generally Daniel Seng, The State of the Discordant Union: An Empirical Analysis of DMCA Takedown Notices, 18 VA. J.L. \& TECH. 369 (2014).

${ }^{109}$ See id. at 395 (discussing the rise of third-party DMCA reporters and reporting agents).

110 Testimony of Katherine Oyama, Sr. Copyright Policy Counsel, Google, Inc., Section 512 of

Title 17: Hearing Before the Subcomm. on Courts, Intellectual Prop., and the Internet of the H. Comm. on the Judiciary, 113th Cong. (2014), at 4-5, available at http://judiciary.house.gov/_cache/files/be93d452-945a-4fff-83ec-b3f51de782b3/031314testimony---oyama.pdf.

111 GoOGLE, supra note 92, at 14.

112 See Dave Lee, Google Changes 'To Fight Piracy' By Highlighting Legal Sites, BBC NEWs, Oct. 20, 2014, http://www.bbc.com/news/technology-29689949.

113 GoOGLE, supra note 92, at 3.

${ }^{114}$ Perfect 10, Inc. v. Google, Inc., No. CV 04-9484 AHM SHX, 2010 WL 9479059, at*1 (C.D. Cal. July 26, 2010) (granting partial summary judgment for Google on its $§ 512(d)$ defense for web and image search).

115 RIAA, Google's New Report: Big on Data, But Where's the Impact?, MUSIC Notes BLOG (Sept. 10, 2013), http://www.riaa.com/blog.php?content_selector=riaa-news-

blog\&blog_selector=wheres-the-impact\&news_month_filter=9\&news_year_filter=2013 (“At least
} 


\section{DRAFT}

Forthcoming in John A. Rothchild (ed.), RESEARCH HANDBOOK ON ELECTRONIC COMMERCE LAW, Edward Elgar, 2016

IFPI, the RIAA, and the MPAA have all demanded that search engine operators work more aggressively to channel users to licensed content services and away from unlicensed ones. ${ }^{116}$ They have also asked Google to alter the operation of the autocomplete function, which predicts the next term in a user's incomplete search query based on how the majority of past users completed queries using the same initial terms. ${ }^{117}$ Over time, Google has acceded to both requests. It altered its PageRank search algorithm in 2012 to take into account the number of DMCAcompliant notices received for a given website. ${ }^{118}$ The PageRank algorithm is proprietary, and beyond stating that the number of DMCA notices received for a given site is "one signal among the hundreds" that it weighs when ranking search results, Google has never disclosed how much weight it gives to this factor. With respect to autocomplete, Google promised in 2010 to prevent terms closely associated with piracy from appearing in autocomplete results. ${ }^{119}$ In 2014 , it began demoting autocomplete predictions that returned search results containing a large number of DMCA-demoted sites. ${ }^{120}$

Copyright owners have been less than pleased with Google's efforts at demoting "pirate sites" in search results. A study commissioned by the MPAA compared the three months before and after implementation of the demotion signal and found that the share of search referrals to the 2,000 sites that appeared most often in DMCA takedown notices actually increased slightly, from nine percent to almost ten percent. ${ }^{121}$ The RIAA released its own "report card" six months after the algorithm change, concluding that "[the demotion] signal does not result in a meaningful change in search rankings of noticed sites on the first page of search

in the case of search results . . . it is increasingly clear we are making insufficient progress against piracy.").

116 IFPI, DigITAL MUSIC REPORT (2013), supra note 112, at 29.

117 See Ernesto, RIAA Wants Google to Implement Five-Point Anti-Piracy Plan, TORRENTFREAK (Jan. 14, 2014), http://torrentfreak.com/riaa-demands-google-deal-with-piracy-140114/ (reporting on the RIAA's demand that Google "[s]top leading users to illegal sites through autocomplete").

118 See Andrea Peterson, How Google Search Is Changing To Fight Online Piracy, WASH. PosT (Oct. 20, 2014), http://www.washingtonpost.com/blogs/the-switch/wp/2014/10/20/how-googlesearch-is-changing-to-fight-online-piracy/.

${ }^{119}$ Kent Walker, Making Copyright Work Better Online, Google Public Policy Blog (Dec. 2, 2010), http://googlepublicpolicy.blogspot.com/2010/12/making-copyright-work-betteronline.html.

${ }^{120}$ Katherine Oyama, Continued Progress on Fighting Piracy, Google PUBLIC PoliCY BLOG (Oct. 17, 2014), http://googlepublicpolicy.blogspot.com/2014/10/continued-progress-on-fightingpiracy.html.

${ }^{121}$ Millward Brown Digital, Understanding the Role OF SEARCh In OnLine PIRACY 10 (2014), available at http://www.mpaa.org/wp-content/uploads/2014/03/Understanding-the-role-ofsearch-in-online-piracy.pdf. 


\section{DRAFT}

Forthcoming in John A. Rothchild (ed.), RESEARCH HANDBOOK ON ELECTRONIC COMMERCE LAW,

results when a user searches for an mp3 or download of popular songs." 122 In 2014, Google reported that it had further refined the DMCA demotion signal in search, but it did not specify the nature of the refinement. ${ }^{123}$ It also pointed out that users do not typically formulate their search queries in the ways tested by the RIAA and MPAA (i.e., with the words "mp3," "free stream," or "download" following a movie or song title); rather, they usually search simply for the name of an artist or the title of a song or movie. ${ }^{124}$ Google search queries formulated as users typically formulate them do not return results with "pirate sites" on the first pages. ${ }^{125}$

\section{Type 2 DMCA-plus enforcement}

Type 2 DMCA-Plus enforcement is comprised of voluntary measures undertaken by intermediaries that fall outside the ambit of the DMCA because their activities do not subject them to secondary copyright liability. Type 2 intermediaries include payment system operators, such as MasterCard, Visa, and PayPal, and advertising networks, such as Google and Yahoo!. These intermediaries give websites the wherewithal to generate revenue, which has made them a logical target for copyright owners seeking to choke the flow of money to "pirate sites." In its 2013 green paper, Copyright Policy, Creativity, and Innovation in the Digital Economy, the Department of Commerce Internet Policy Task Force identified the "follow the money" approach as one among several "potential new tools" for addressing "the gaps and shortcomings in existing legal tools" for fighting online piracy. ${ }^{126}$

"Existing legal tools" do not capture Type 2 intermediaries because their relationship to direct infringers and acts of direct infringement is too attenuated. That, at any rate, is what the Ninth Circuit Court of Appeals held in Perfect $10 v$. Visa, a closely watched case that tested the reach of copyright's secondary liability

\footnotetext{
122 RIAA, SiX MONTHS LATER - A REPORT CARD ON GOOGLE's DEMOTION OF PIRATE SiTES 2 (2013), available at http://riaa.com/media/3CF95E01-3836-E6CD-A470-1C2B89DE9723.pdf.

123 GOOGLE, supra note 92, at 18.

${ }^{124} I d$. at 19.

${ }^{125} \mathrm{Id}$.

${ }^{126}$ DEP'T OF COMMERCE INTERnET POLICY TASK ForCE, COPYRIGHT POLICY, CREATIVITY, AND INNOVATION IN THE DIGITAL ECONOMY 61, 67-70 (2013), available at http://www.uspto.gov/sites/default/files/news/publications/copyrightgreenpaper.pdf.
} 


\section{DRAFT}

Forthcoming in John A. Rothchild (ed.), RESEARCH HANDBOOK ON ELECTRONIC COMMERCE LAW,

rules in the e-commerce environment. ${ }^{127}$ Perfect 10 argued that Visa was contributorily and vicariously liable for infringement of its copyrighted images because Visa accepted payments from websites on which those infringements occurred. ${ }^{128}$ The court rejected Perfect 10's argument as to both theories of secondary liability. On the question of contributory infringement, it held that having "the power to undermine the commercial viability of infringement" does not constitute material contribution to infringement or inducement to infringe. ${ }^{129}$ The court's conclusion that Visa and other payment-industry defendants could not be held liable as contributory infringers rested in part on the finding that they did not aid users in locating infringing material — unlike search engines - and in part on the finding that they did not store or route any infringing material on or across their payment networks. ${ }^{130}$ On the question of vicarious infringement, the court held that a payment processor's ability to affect online infringement by making it less profitable is not the same as an ability to supervise and control infringing activity, which is required for vicarious liability. ${ }^{131}$ The same reasoning extends to advertising networks, which are situated similarly to payment systems in terms of their relationship to the infringing activities that occur on their customers' websites: although advertising networks have the power to make direct infringement on thirdparty websites less profitable, they do not provide the site or facilities for infringing acts, and they do not have the ability to control or supervise those acts. ${ }^{132}$

From a policy perspective, well-defined and carefully circumscribed secondary liability rules are necessary to prevent the unfairness that could easily result from making one party pay for another's bad acts. ${ }^{133}$ Rights owners, however,

\footnotetext{
${ }^{127}$ Perfect 10, Inc. v. Visa Int'l Serv. Ass’n, 494 F.3d 788 (9th Cir. 2007). Judge Kozinski filed a sharp dissent in the case, and legal scholars have recognized the extent to which the outcome was policy driven in the face of unstable doctrine. See Mark Bartholomew \& Patrick F. McArdle, Causing Infringement, 64 VAND. L. REV. 675, 711 (2011).

${ }^{128}$ Perfect 10, 494 F.3d at 792.

${ }^{129} \mathrm{Id}$. at 800 .

${ }^{130} \mathrm{Id}$.

${ }^{131}$ See id. at 804 ("Defendants ... cannot take away the tools the offending websites use to reproduce, alter, and distribute the infringing images over the Internet. They can only take away the means the websites currently use to sell them.").

132 A disclaimer to this effect appears in the opening paragraphs of the best practices document that advertising networks adopted in 2013. See BEST PRACTICES GUIDELINES FOR AD NETWORKS TO ADDRESS PIRACY AND COUNTERFEITING 1, available at http://blog.aol.com/2013/07/15/adnetworks-best-practices/ ("Ad Networks do not control the content on third-party websites and are not able to remove websites from the Internet.").

${ }^{133}$ See Sony Corp. of Am. v. Universal City Studios, Inc., 464 U.S. 417, 435 (1984) (acknowledging that secondary infringement liability presents the "problem of identifying the circumstances in which it is just to hold one individual accountable for the actions of another").
} 


\section{DRAFT}

Forthcoming in John A. Rothchild (ed.), RESEARCH HANDBOOK ON EleCtronic COMMERCE LAW,

view limitations on the scope of secondary liability for Type 2 intermediaries as a bug, not a feature of copyright law. They believe that "all players in the Internet ecosystem," meaning everyone in a position to do anything to reduce infringement, should function as deputy enforcers, regardless of their ability to directly control infringing content. ${ }^{134}$ In 2011, with prodding from IPEC, five major payment networks - American Express, Discover, MasterCard, Visa, and PayPal - agreed to a set of voluntary best practices to combat online piracy and counterfeiting. ${ }^{135} \mathrm{In}$ 2013, the major online advertising networks-AOL, Google, Microsoft, and Yahoo!- did the same. ${ }^{136}$

A. Notice and termination by payment processors

Payment processors implemented their best practices agreement in January 2012 with the launch of the Payment Processor Initiative, an inter-industry enforcement effort run by the International AntiCounterfeiting Coalition ("IACC") under the registered trademark "RogueBlock." ${ }^{137}$ Following the program's initial implementation, PULSE and Diners Club joined. ${ }^{138}$

The IACC's role in administering the RogueBlock Payment Processor Initiative is roughly analogous to the role that CCI plays in administering CAS. ${ }^{139}$ Similar to the graduated response protocol in CAS, to which broadband users become bound through terms of service with their providers, the enforcement protocol in the best practices agreement becomes binding on merchants through payment processors' policies, which prohibit the use of card services for illegal

${ }^{134}$ Comments of the MPAA, supra note 8, at 2.

135 See IPEC 2013 JOINT STRATEGIC PLAN, supra note 12, at 36.

${ }^{136}$ See Victoria Espinel, Coming Together to Combat Online Piracy and Counterfeiting, WHITE HousE BLOG (July 15, 2013), https:/www.whitehouse.gov/blog/2013/07/15/coming-togethercombat-online-piracy-and-counterfeiting.

${ }^{137}$ See IACC Payment Processor Initiative, IACC, http://www.iacc.org/rogueblock.html (stating that "[ $\mathrm{t}]$ he initiative launched in January 2012, following rights-holder negotiations with the payment industry to develop a set of best practices in addressing rogue websites, as encouraged by the U.S. Intellectual Property Enforcement Coordinator, Victoria Espinel").

138 See Payment Processor Initiative \& Portal Program, https://web.archive.org/web/20130119105913/http://c.ymcdn.com/sites/members.iacc.org/resourc e/resmgr/IACC_PaymentProcessorInitiat.pdf (listing participating payment processors).

${ }^{139}$ See Bridy, Graduated Response American Style, supra note 34, at 27-30 (explaining the role of the Center for Copyright Information). 


\section{DRAFT}

Forthcoming in John A. Rothchild (ed.), RESEARCH HANDBOOK ON ELECTRONIC COMMERCE LAW, Edward Elgar, 2016

transactions. ${ }^{140}$ There is, however, a very important difference between the voluntary best practices agreement for payment processors and the MOU that created CAS: the former is, by its express terms, not legally binding on the participating parties. ${ }^{141}$ Although the terms of the agreement are sufficiently specific to be enforced, the parties disclaim contractual intent.

At the core of the best practices agreement for payment processors is a notice-and-termination protocol. The protocol is operationalized through the RogueBlock "Portal Program," which is a web-based software system for managing communications between rights owners and payment processors concerning alleged "rogue sites." 142 Copyright and trademark owners pay annual fees for access to the program. ${ }^{143}$ The program's front end is a secure online portal through which participating rights owners submit complaints containing information specified in the best practices agreement. ${ }^{144}$ The Portal provides a standardized, fillable web form for this purpose. ${ }^{145}$ On the program's back end, the IACC reviews complaints and relays them to the relevant payment processor, which takes action as specified in the best practices agreement. ${ }^{146}$ The payment processor then reports back to the IACC about the outcome of each complaint. Rights owners can track the status of complaints and view outcomes via the online portal. ${ }^{147}$

A complaint from a rights owner under the agreement must contain four elements to be actionable: (1) a description of the alleged infringement and the "Illegitimate Products," including the identity of the website in question; (2) evidence that infringing products are available on the website using the payment processor's services (e.g., a screenshot of a payment processor's logo on the site); (3) a copy of a cease-and-desist letter or DMCA notice from the rights owner

\footnotetext{
140 See Kristina Montanaro, IACC PAYMEnT Processor Portal Program: FIRST YeAR STATISTICAL REVIEW 3 (2012), available at http://www.gacg.org/Content/Upload/MemberNewsDocs/October\%202012\%20Report\%20to\%20 IPEC\%20-\%20FINAL.pdf ("The Portal Program is dependent on Card Network policies, which prohibit merchants from using card services for illegal transactions. Use of card services for sales of counterfeit or pirated goods constitutes a breach of these policies, and thus provides for remediation of the corresponding merchant account.").

${ }^{141}$ See BEST PRACTICES TO ADDRESS COPYRIGHT INFRINGEMENT AND THE SALE OF COUNTERFEIT PRODUCTS ON THE INTERNET 4 (May 16, 2011) ("These best practices are voluntary and not legally binding.") (on file with author).

${ }^{142}$ See IACC Payment Processor Initiative, supra note 145.

${ }^{143}$ Payment Processor Initiative \& Portal Program, supra note 146.

${ }^{144} \mathrm{Id}$.

145 See Montanaro, supra note 147, at 5 (reproducing a screen shot of the standardized form).

146 See Payment Processor Initiative \& Portal Program, supra note 145.

${ }^{147} I d$.
} 


\section{DRAFT}

Forthcoming in John A. Rothchild (ed.), RESEARCH HANDBOOK ON ELECTRONIC COMMERCE LAW,

notifying the website's owner of the allegation of infringement, or an attestation that, to the best of the rights owner's knowledge, the site is not licensed or authorized to distribute the products; and (4) evidence that the requester owns the copyright or trademark in question. ${ }^{148}$ If the payment processor requires additional information concerning the complaint, the rights owner must provide the information promptly. ${ }^{149}$ The agreement does not require test transactions as part of the complaint submission. ${ }^{150}$ Nor does it require any pre-complaint direct communication between the rights owner and the accused merchant.

Upon receiving a complaint, the payment processor must conduct an investigation. ${ }^{151}$ Once a complaint has been filed, the agreement puts the onus on the accused merchant to produce "credible evidence" that it is not engaged in infringing transactions. ${ }^{152}$ If the merchant fails to respond or doesn't meet its burden, or if the payment processor "determines in its reasonable opinion that the merchant is engaged in sales of Illegitimate Products," then the merchant is ordered to block future infringing transactions. ${ }^{153}$ If the merchant continues to engage in such transactions, then the payment processor "shall suspend or terminate payment services to that merchant with United States account holders." 154 The agreement contemplates but does not specify additional "appropriate remedies."155 Termination is the typical sanction. ${ }^{156}$

For merchants that believe they have been wrongly sanctioned, payment processors must "have a process in place to allow for prompt review of remedial measures." "The agreement is silent, however, as to what or how much process is due when a merchant requests a review. There is no provision for third-party review

\footnotetext{
148 BeSt PRACTICES TO AdDRESS COPYRIGHT INFRINGEMENT AND THE SALE OF COUNTERFEIT PRODUCTS ON THE INTERNET, supra note 148, at 1-2.

149 Id. at 2.

${ }^{150} \mathrm{Id}$. at 1.

${ }^{151}$ Id. at 2.

${ }^{152}$ Id. .

${ }^{153} I d$.

${ }^{154} I d$.

${ }^{155} \mathrm{Id}$. at 3.

${ }^{156}$ See Payment Processor Initiative \& Portal Program, supra note 145 ("How do I know the results of my submitted claims? The information received back from the Trace Message will identify the merchant processing the transactions. Typically, that merchant is then terminated. . $. ")$.

${ }^{157}$ BEST PRACTICES TO ADDRESS COPYRIGHT INFRINGEMENT AND THE SALE OF COUNTERFEIT PRODUCTS ON THE INTERNET, supra note 148, at 3.
} 


\section{DRAFT}

Forthcoming in John A. Rothchild (ed.), RESEARCH HANDBOOK ON ELECTRONIC COMMERCE LAW,

Edward Elgar, 2016

or for a stay of termination pending resolution of the review. ${ }^{158}$ In cases where the merchant disputes termination, and the payment processor reasonably concludes that the accused merchant is operating legitimately, the agreement implicitly contemplates that the payment processor may nevertheless impose or sustain termination if the rights owner is willing to indemnify it for any resulting legal liability. ${ }^{159}$ This risk-shifting provision effectively gives the complaining rights owner final say over termination decisions.

In 2013 , the IACC reported that 26,000 payment channels ${ }^{160}$ on 7,500 accused websites and over 2,100 individual merchant accounts had been terminated. ${ }^{161}$ The cost of account termination for a merchant is high, considering that it can take at least a week to establish a new merchant account, assuming the terminated merchant can meet the due-diligence requirements of a new cardservicing bank. ${ }^{162}$ Given the high cost of error for a terminated merchant, it is troubling that the payment processors' best practices agreement provides no stay of termination pending review and no specific set of dispute-resolution procedures for merchants that contest termination of their accounts. And because payment processors can look to rights owners for indemnification if a merchant decides to fight termination, error costs for payment processors are relatively low, which may create an incentive for them to overblock.

B. Notice and termination by advertising networks

\footnotetext{
${ }^{158}$ This is in contrast with the CAS, which provides for a stay of sanctions pending review. See Bridy, Graduated Response American Style, supra note 34, at 33-37 (explaining the process for appealing a mitigation measure in CAS).

159 See BEST PRACTICES TO ADDRESS COPYRIGHT INFRINGEMENT AND THE SALE OF COUNTERFEIT PRODUCTS ON THE INTERNET, supra note 148, at 3 ("A Payment System Operator may request a written agreement by the Right-Holder to support the Payment System Operator fully in connection with a dispute where, in the Payment System Operator's reasonable opinion, the merchant provides credible evidence supportive of the merchant's position that it is not engaged in illegal conduct, including by defending, holding harmless and indemnifying the Payment System Operator for any costs, expenses (including legal fees) or liabilities arising in connection with such dispute.").

${ }^{160}$ A website has multiple payment channels if it accepts cards or payments from multiple payment processors.

${ }^{161}$ Role of Voluntary Agreements in the U.S. Intellectual Property System, supra note 12, at 56 (Written Testimony of Robert C. Barchiesi on Behalf of the IACC, at 5).

${ }^{162}$ Montanaro, supra note 147 , at 14.
} 


\section{DRAFT}

Forthcoming in John A. Rothchild (ed.), RESEARCH HANDBOOK ON ELECTRONIC COMMERCE LAW,

The voluntary best practices agreement for advertising networks is less detailed in its prescriptions than the one for payment processors, but it incorporates the same basic notice-and-termination protocol and becomes binding on a network's customers in the same way-through terms of service. Each network agrees as an initial matter to maintain and publish policies prohibiting network participation by websites that are "principally dedicated to . . . engaging in copyright piracy and have no substantial non-infringing uses." 163 There is no central clearinghouse or portal for administering the advertising network best practices; instead, each participating network agrees to establish and implement its own internal procedures. This differs from the IACC's "one size fits all" implementation for payment processors. As in the best practices agreement for payment processors, the best practices agreement for advertising networks expressly disclaims contractual intent. ${ }^{164}$ It also expressly disclaims any affirmative monitoring obligation, essentially importing the DMCA's no-duty-to-monitor rule. ${ }^{165}$

A copyright owner initiates the notice and termination process by filing a complaint with a participating advertising network. ${ }^{166}$ To be actionable, a complaint must contain six elements, many of which overlap with the elements of a DMCA notice under Section 512(c)(3)(A): (1) a description of the alleged illegitimate activity, including the specific URL where the activity is occurring, and contact information for the accused website; (2) evidence of the allegedly infringing activity in the form of a time-and-date stamped screenshot of the website showing an advertisement from the network displayed on the site; (3) a copy of a DMCA notice or a cease-and-desist letter sent to the operator of the website; (4) a statement under penalty of perjury that the complainant has a good faith belief that the allegedly infringing activity is unauthorized, and that the complainant is either the copyright owner or the copyright owner's authorized agent; (5) contact information for the copyright owner; and (6) a physical or electronic signature of the complainant. ${ }^{167}$ Unlike the best practices for payment processors, which do not condition the filing of a complaint on any prior contact between the complainant and the targeted website, the best practices for advertising networks require a complainant to have contacted the accused website operator first. This policy

\footnotetext{
${ }^{163}$ Best PRACTICES Guidelines For AD NeTWORKS, supra note 139, at 2.

${ }^{164} \mathrm{Id}$. at 3 (" $[\mathrm{I}] \mathrm{t}$ is understood that the voluntary best practices reflected in this Statement should not, and cannot, be used in any way as the basis for any legal liability or the loss of any applicable immunity....").

${ }^{165} I d$.

${ }^{166} I d$. at 2.

${ }^{167} I d$. at $4-5$.
} 


\section{DRAFT}

Forthcoming in John A. Rothchild (ed.), RESEARCH HANDBOOK ON ELECTRONIC COMMERCE LAW, Edward Elgar, 2016

reflects the principle, made explicit in the agreement, that best practices should "encourage and supplement, not replace, responsible and direct independent actions taken by intellectual property owners to enforce their intellectual property rights." 168

Following receipt of a sufficiently specific complaint, the advertising network undertakes an "appropriate investigation." 169 In its investigation, the network may consider any credible evidence submitted by the accused website to rebut the claim that it is principally dedicated to piracy and lacks substantial noninfringing uses. ${ }^{170}$ Such evidence may consist of a DMCA counter-notice-yet another instance of conscious parallelism between the ad network best practices and the DMCA. ${ }^{171}$ If, after investigation, the network concludes that the complaint was legitimate, it may impose one of a number of sanctions: it may ask the accused website to stop engaging in infringing activity; it may stop serving ads on the accused website as whole, or only on certain pages within the website, until it verifies that the infringing activity has stopped; or it may terminate the website from the network. ${ }^{172}$ Unlike the best practices for payment processors, the best practices for advertising networks do not include any review or appeal process for a website that wishes to contest an adverse finding against it. The threshold for an adverse finding is much higher with advertising networks, however, than it is with payment processors; payment processors terminate merchants without first having to find that their websites are principally dedicated to piracy and lack substantial non-infringing uses.

Public interest groups view the advertising networks' strict standard for termination favorably, because it limits non-judicial enforcement to clear-cut cases involving demonstrably bad actors, leaving close or ambiguous cases to traditional dispute resolution fora. ${ }^{173}$ The MPAA, by contrast, is critical of the advertising networks' best practices, complaining that they "place nearly all of the burden of ensuring that ads do not appear on sites dedicated to piracy upon rightsholders." That allocation of burdens, in which copyright owners are primarily responsible for

\footnotetext{
${ }^{168} I d$. at 1.

${ }^{169} \mathrm{Id}$. at 3 .

${ }^{170} \mathrm{Id}$.

${ }^{171} I d$. For the required elements of a DMCA counter-notice, see 17 U.S.C. $\S 512(\mathrm{~g})(3)$.

${ }^{172} I d$.

${ }^{173}$ See, e.g., David Sohn, Ad Networks Pledge Voluntary Practices Against Piracy, CTR. FOR DEMOCRACY \& TECH. BLOG (July 16, 2013), https://cdt.org/blog/ad-networks-pledge-voluntarypractices-against-piracy/.

${ }^{174}$ Comments of the MPAA, supra note 8 , at 5 .
} 


\section{DRAFT}

Forthcoming in John A. Rothchild (ed.), RESEARCH HANDBOOK ON ELECTRONIC COMMERCE LAW,

Edward Elgar, 2016

enforcing their own rights online, is consistent with the congressional intent expressed in the DMCA. ${ }^{175}$ It appears skewed only when viewed from the DMCAplus perspective that rights owners and online intermediaries are somehow equally responsible for online enforcement and equally well situated (if intermediaries are not better situated) to undertake it. Notably, the DMCA-plus perspective represents a significant departure from existing secondary liability doctrines in intellectual property law. ${ }^{176}$

\section{Conclusion}

The DMCA-plus era of online copyright enforcement is well underway. In this post-DMCA world, online intermediaries of all shapes and sizes face increasing pressure to do more than the law requires of them to police intellectual property rights. DMCA-plus arrangements can be beneficial if they are truly voluntary and reflect genuine consensus among copyright owners and Internet companies about how and why to adjust the obligations that flow from default liability rules and exceptions. For large Internet companies that have the infrastructure and economic wherewithal to implement DMCA-plus measures, such measures may be a reasonable way to simultaneously avoid new governmental regulation and secure new business opportunities. New entrants and smaller players may be disadvantaged, however, to the extent that DMCA-plus measures adopted by major intermediaries like Google, Comcast, and PayPal up the ante for everyone.

DMCA-plus enforcement also raises a range of normative concerns for Internet users and merchants: "Best practices" agreements are negotiated privately, without input from the public or public interest groups. In this respect, they lack the

\footnotetext{
175 See UMG Recordings, Inc. v. Shelter Capital Partners LLC, 718 F.3d 1006, 1022 (9th Cir. 2013) ("Congress made a considered policy determination that the DMCA . . would place the burden of policing copyright infringement ... squarely on the owners of the copyright.") (internal citation and quotation marks omitted); Viacom Int'l Inc. v. YouTube, Inc., 718 F. Supp. 2d 514, 523 (S.D.N.Y. 2010) ("[I]mpos[ing] responsibility on service providers to discover which of their users' postings infringe a copyright would contravene the structure and operation of the DMCA."), aff'd in part, vacated in part, remanded, 676 F.3d 19 (2d Cir. 2012).

${ }^{176}$ Courts in cases involving contributory trademark infringement claims against online intermediaries have also rejected the argument that intermediaries, as putative "cheaper cost avoiders," should bear the primary burden of policing trademarks online. See Tiffany (NJ) Inc. v. eBay, Inc., 576 F. Supp. 2d 463, 518 (S.D.N.Y. 2008) ("[E]ven if it were true that eBay is best situated to staunch the tide of trademark infringement to which Tiffany and countless other rights owners are subjected, that is not the law."), aff'd in part, rev'd in part, 600 F.3d 93 (2d Cir. 2010).
} 


\section{DRAFT}

Forthcoming in John A. Rothchild (ed.), RESEARCH HANDBOOK ON ELECTRONIC COMMERCE LAW,

deliberative transparency associated with public law-making. The protocols they prescribe often presume liability for the accused and entail rushed or summary adjudications by inexpert authorities. Such protocols may thus be procedurally inadequate to prevent the removal of non-infringing content or the punishment of innocent actors. For the Internet as a whole to benefit from DMCA-plus enforcement, "best practices" must incorporate adequate protections for Internet users and online merchants, whose interests are at risk of being marginalized when copyright owners and online intermediaries hammer out new bargains under IPEC's watchful eye. 